\title{
RELACIÓN ENTRE LOS VIRUS INFORMATICOS (MALWARE) Y ATAQUES EN PAISES VULNERABLES DE SEGURIDAD EN INFORMATICA UTILIZANDO ANÁLISIS DE COMPONENTES PRINCIPALES (ACP) \\ Relationship between computer viruses (malware) and attacks vulnerable countries using computer security with Principal Component Analysis (PCA)
}

\author{
Autor: Alain Donuhue Dongo Quintana \\ alain.dongo@gmail.com \\ Docente Facultad de Ingeniería UCSS \\ ClO Strategy $\mathrm{TI}$ \\ Lima, Febrero, 2016
}

\begin{abstract}
RESUMEN: Utilizando información de Karpesky Lab el presente artículo se observa que a través de Análisis de Componentes Principales (ACP) existe una la relación de ciertos virus informáticos sobre todo los malware en los países más vulnerables en seguridad de informática, donde se arroja como resultados que el país Argelia es el más atacado por virus troyanos, mientras que los países como Ucrania y Uzbekistán son más propensos a infectarse con virus a través de internet, se nota también que Corea del Sur como China son más atacados por los virus con intentos de infección, finalmente Bielorrusia es el país donde a través de sus PC's tienen demasiado riesgo a contagiarse de virus. Para este análisis se ha utilizado para el cálculo el software libre R Statistics, así como también el Rattle como una herramienta de Minería de Datos.
\end{abstract}

ABSTRACT Using data from Kaspersky Lab this article notes that through Principal Component Analysis (PCA ) there is the relationship of certain computer viruses especially malware in the most vulnerable countries where it is observed that the country Algeria is the most attacked by Trojan viruses, while countries like Ukraine and Uzbekistan are more likely to become infected with the virus through internet, it also notes that South Korea and China are attacked by the virus infection attempts, Bielorusia is the last country where through their PCs have too much risk of catching viruses.

For this analysis was used to calculate the free software R Statistics and Rattle as a data mining tool

\section{Introducción:}

A medida que aumentan el número y la gravedad de los crímenes cibernéticos, es importante conocer los diversos tipos de ataque como el malware (del inglés "malicious software", también llamado badware, código maligno, software malicioso o software malintencionado, es un tipo de software que tiene como objetivo infiltrarse 0 dañar una computadora o sistema de información sin el consentimiento de su propietario). En el presente artículo se analizan los factores que actualmente impulsan el desarrollo de malware, se exponen en detalle las características de cada uno de ellos, se describe cómo se manifiestan en la red y se explica cómo pueden remediarse.

Aunque los nombres de algunos tipos de malware pueden resultarnos familiares, estas amenazas evolucionan constantemente, obligando a todo aquel que desee garantizar la seguridad de su sistema a adaptarse a estos continuos cambios. Los principales métodos utilizados por estos cibercriminales incluyen: La extorsión. Consiste en bloquear computadoras o interrumpir su funcionamiento para posteriormente cobrar dinero por solucionar los supuestos problemas.

En este tipo de ataques, a menudo se realizan escaneos inútiles de las computadoras o se vende software "antivirus" igualmente inútil. Esta técnica puede utilizarse para obtener información de tarjetas de crédito. En ocasiones, el software que adquieren las víctimas es "scareware", que les lleva a comprar otros supuestos productos de software o a pagar servicios de suscripción inútiles. El robo de recursos electrónicos. Entre los recursos electrónicos que se roban con mayor frecuencia se encuentran los datos de identificación personal (robo de identidad) de los registros de empleados o de clientes; información y contraseñas de cuentas financieras; datos comerciales y de negocio propietarios que pueden venderse a competidores; cuentas de correo electrónico -incluidos los contactos-, que pueden utilizarse para enviar mensajes spam (desde fuentes aparentemente fiables); e incluso recursos informáticos propiamente dichos (zombies), que son controlados por los criminales para perpetrar todo tipo de ataques: desde mensajes spam hasta el hospedaje de contenidos pornográficos. El software utilizado para cometer este tipo de crímenes pertenece a la categoría de malware.

Ante ello con la información brindada por Karspesky Lab interesa investigar la relación entre los ataques de los virus troyanos y el resto de variables, utilizando Análisis de Componentes Principales (ACP) donde se ha realizado con el objetivo transformar un conjunto de variables originales, en un nuevo conjunto de variables (sin perder información), combinación lineal de las originales, denominadas componentes principales (factores) para ver la relación que hay entre los países más vulnerables frente a los ataques de los virus informáticos con la información utilizada de Kasperesky Lab del 2do Trimestre del año 2015 


\section{Estadísticas}

**Todos los datos estadísticos usados en el informe se han obtenido mediante la red antivirus distribuida Kaspersky Security Network (KSN) como resultado del funcionamiento de los diferentes componentes de protección contra los programas maliciosos. Los datos se obtuvieron en los equipos de los usuarios de KSN que confirmaron su consentimiento en enviarlos. En el intercambio global de información sobre las actividades maliciosas toman parte millones de usuarios de los productos de Kaspersky Lab de 213 países del mundo.

\section{Amenazas para dispositivos móviles}

Los programas maliciosos bancarios móviles siguen siendo una de las principales amenazas móviles. En el informe del primer trimestre de 2015 según Kaspersky Lab sobre el troyano Trojan-SMS.AndroidOS.OpFake.cc, que sabía atacar como mínimo a 29 bancos e instituciones financieras. La versión más reciente de este troyano puede atacar a 114 instituciones bancarias y financieras. Su principal objetivo es robar el login y contraseña de la cuenta. Con el mismo fin ataca a varias aplicaciones de correo populares.

\section{Cantidad de las nuevas amenazas móviles}

En el segundo trimestre de 2015 Kaspersky Lab ha detectado 291887 nuevos programas maliciosos móviles, 2,8 veces más que en el primer trimestre de 2015.

Con esto, la cantidad de paquetes maliciosos detectados fue de 1048129, que es 7 veces más que en el trimestre anterior.

\section{Número de paquetes de instalación y nuevos programas nocivos móviles detectados \\ (del cuarto trimestre de 2014 al segundo de 2015)}

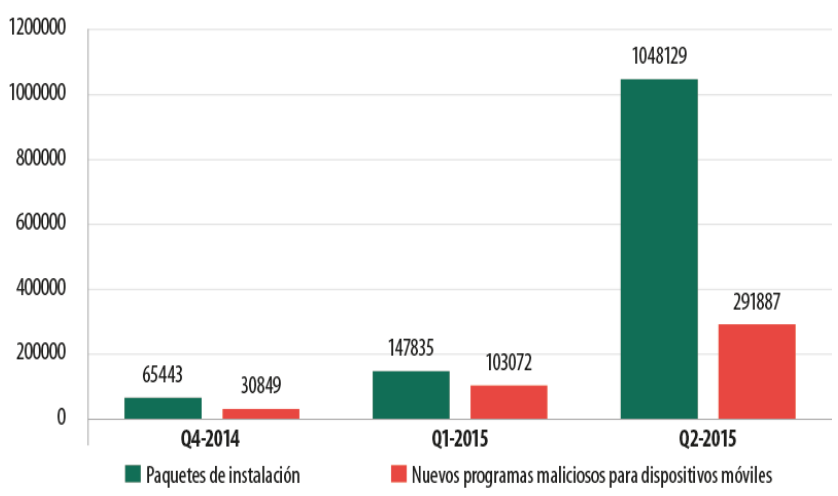

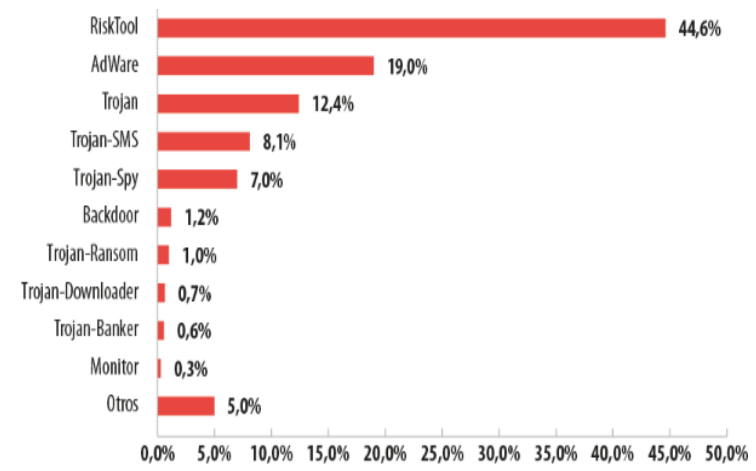

Distribución por tipos de los nuevos programas
maliciosos móviles, segundo trimestre de 2015

RiskTool (44,6\%) lidera la estadística de los programas maliciosos para dispositivos móviles detectados en el segundo trimestre de 2015. Se trata de aplicaciones legales que son potencialmente peligrosas para los usuarios: su uso malicioso o irresponsable por parte del dueño del teléfono inteligente puede causar pérdidas financieras al usuario. En el segundo puesto está la categoría Adware, formada por programas publicitarios potencialmente indeseables (19\%).

Los troyanos SMS que durante largo tiempo lideraron en esta estadística, en el segundo trimestre ocuparon sólo el cuarto puesto con un $8,1 \%$. Esto es un $12,9 \%$ menos que en el primer trimestre. La reducción del porcentaje de este tipo de malware está condicionada por el hecho de que las personas que antes propagaban activamente los troyanos SMS empezaron a usar métodos más transparentes de monetización (de lo que da fe el crecimiento del porcentaje de RiskTool), o bien han preferido usar programas maliciosos de otros tipos. Así, la participación de los troyanos ha crecido del $9,8 \%$ en el primer trimestre al $12,4 \%$ en el segundo.

TOP 10 de países por la cantidad de usuarios atacados por troyanos bancarios móviles, del total de todos los usuarios atacados

\begin{tabular}{|c|c|}
\hline País* & $\begin{array}{l}\text { Porcentaje de usuarios } \\
\text { atacados en este país, del total } \\
\text { de los usuarios atacados }\end{array}$ \\
\hline $\begin{array}{l}\text { Corea del } \\
\text { Sur }\end{array}$ & $31,72 \%$ \\
\hline 2 Rusia & $10,35 \%$ \\
\hline 3 Australia & $6,62 \%$ \\
\hline 4 Austria & $6,03 \%$ \\
\hline 5 Japón & $4,73 \%$ \\
\hline 6 Uzbekistán & $4,17 \%$ \\
\hline 7 Bielorrusia & $3,72 \%$ \\
\hline 8 Ecuador & $3,50 \%$ \\
\hline 9 Ucrania & $3,46 \%$ \\
\hline 10 Suiza & $3,09 \%$ \\
\hline
\end{tabular}


** Porcentaje de usuarios únicos en el país atacados por troyanos bancarios móviles, en relación al total de usuarios únicos de este país atacados por malware móvil.

\section{Intentos de infección por programas maliciosos móviles en el segundo trimestre de 2015 (porcentaje del total de usuarios atacados)}

TOP 10 de países según el porcentaje de usuarios atacados por intentos de infección por los troyanos bancarios móviles:

\begin{tabular}{llc}
\hline \multicolumn{1}{c}{ País $^{\star}$} & \% de usuarios atacados \\
\hline 1 & China & $16,34 \%$ \\
\hline 2 & Malasia & $12,65 \%$ \\
\hline 3 & Nigeria & $11,48 \%$ \\
\hline 4 & Bangladesh & $10,89 \%$ \\
\hline 5 & Tanzania & $9,66 \%$ \\
\hline 6 & Argelia & $9,33 \%$ \\
\hline 7 & Uzbekistán & $8,56 \%$ \\
\hline 8 & Rusia & $8,51 \%$ \\
\hline 9 & Ucrania & $8,39 \%$ \\
\hline 10 & Bielorrusia & $8,05 \%$ \\
\hline
\end{tabular}

** Porcentaje en el país de usuarios únicos atacados por los troyanos bancarios móviles, del total de usuarios del antivirus móvil de Kaspersky Lab en el país.

El líder de esta lista es China, donde durante el trimestre el $16,34 \%$ de los usuarios de nuestro producto sufrieron ataques por lo menos una vez. En el segundo puesto está Malasia, con un $12,65 \%$. Rusia $(8,05 \%)$, Ucrania $(8,39 \%)$ y Bielorrusia (8,05\%) cierran el TOP 10, por debajo de los países de Asia y África.

En esta lista Corea ocupó el undécimo lugar con un 7,46\%. Recordamos que en Corea los troyanos bancarios móviles son muy populares entre los delincuentes: son responsables de haber atacado al $31,72 \%$ del total de usuarios atacados por malware móvil.

\section{Aplicaciones vulnerables usadas por los delincuentes}

La siguiente clasificación de las aplicaciones vulnerables se basa en los datos de los exploits usados por los delincuentes tanto en los ataques mediante Internet como en las aplicaciones locales afectadas, entre ellas en los dispositivos móviles de los usuarios, y que bloquearon nuestros productos.

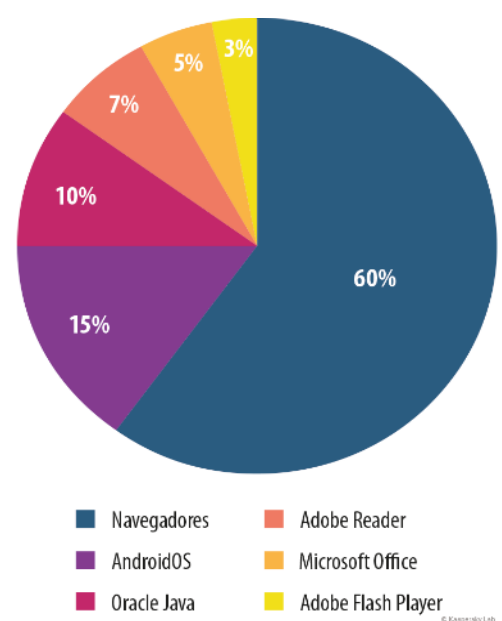

Distribución de los exploits usados en los ataques de los delincuentes, según tipos de aplicaciones atacadas, segundo trimestre de 2015

La distribución de los exploits casi no ha cambiado en comparación con el primer trimestre. Siguen liderando la estadística los exploits para navegadores de Internet (60\%). En este momento la mayoría de los paquetes de exploits contienen exploits para Adobe Flash Player e Internet Explorer. Cabe destacar el aumento significativo en el número de exploits para Adobe Reader (+6 puntos porcentuales). Esto está relacionado con la gran cantidad de envíos de spam que contienen documentos PDF maliciosos.

\section{Programas maliciosos en Internet (ataques mediante la web)}

Los datos estadísticos de este capítulo han sido recopilados por el antivirus web, que protege a los usuarios cuando descargan objetos maliciosos de una página web maliciosa o infectada. Los delincuentes crean sitios maliciosos adrede, pero también los sitios legítimos se pueden infectar si su contenido lo crean los usuarios (como en el caso de los foros), o si son víctimas de hackeo.

\section{Amenazas online en el sector bancario}

En el segundo trimestre de 2015 las soluciones de Kaspersky Lab neutralizaron los intentos de ejecución de programas maliciosos que roban dinero mediante el acceso a cuentas bancarias en los equipos de 755642 usuarios. En comparación con el trimestre anterior (929 082) este índice ha disminuido en un 18,7\%. En el segundo trimestre de 2014 afectó a 735428 equipos.

En total, los productos de Kaspersky Lab han registrado durante el año 5903377 notificaciones sobre intentos de infección con programas maliciosos que roban dinero de las cuentas bancarias online. 


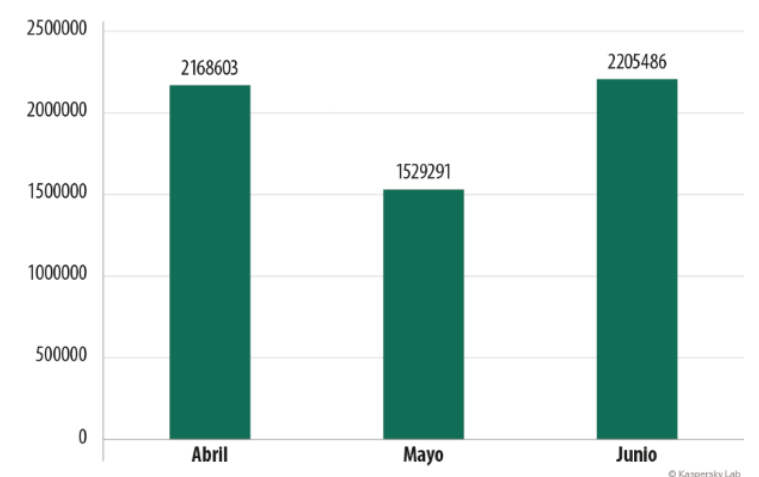

Número de ataques del software financiero malicioso contra los usuarios, segundo trimestre de 2015

\section{Territorios de los ataques}

Para evaluar y comparar el riesgo de infección con troyanos bancarios al que están expuestos las computadoras de los usuarios en diferentes países del mundo, ellos han calculado para cada país el porcentaje de usuarios de productos de Kaspersky Lab que se vieron afectados por esta amenaza en durante el trimestre.

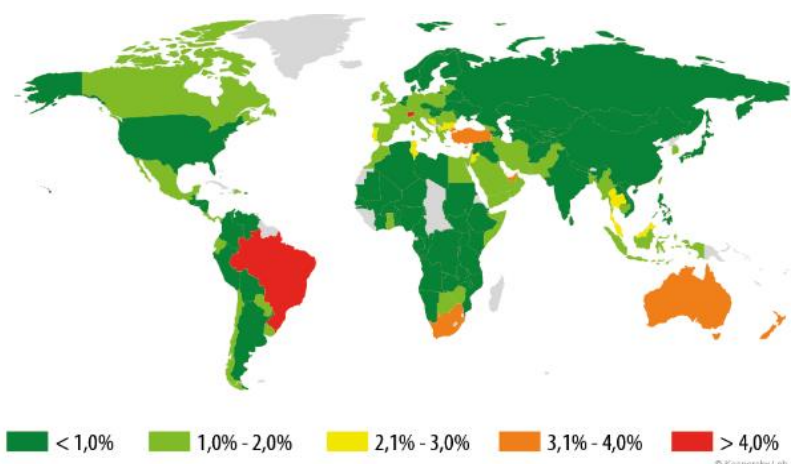

Territorios afectados por los ataques del software malicioso en el segundo trimestre de 2015 (porcentaje de usuarios atacados)

TOP-10 de países según el porcentaje de usuarios atacados

\begin{tabular}{llc}
\hline \multicolumn{1}{c}{ País* } & $\begin{array}{c}\% \text { de usuarios } \\
\text { atacados** }\end{array}$ \\
\hline 1 Singapur & $5,28 \%$ \\
\hline 2 Suiza & $4,16 \%$ \\
\hline 3 Brasil & $4,07 \%$ \\
\hline 4 Australia & $3,95 \%$ \\
\hline 5 Hong-Kong & $3,66 \%$ \\
\hline 6 Turquía & $3,64 \%$ \\
\hline 7 Nueva Zelanda & $3,28 \%$ \\
\hline 8 África del Sur & $3,13 \%$ \\
\hline 9 Líbano & $3,10 \%$ \\
\hline 10 Emiratos Árabes & $3,04 \%$ \\
\hline
\end{tabular}

${ }^{*}$ Porcentaje de usuarios únicos que fueron víctimas de ataques web, de entre el total de los usuarios únicos de los productos de Kaspersky Lab en el país.

En el segundo trimestre de 2015 Singapur es el país que está en el primer lugar por la cantidad de usuarios de Kaspersky Lab atacados por troyanos bancarios. Cabe destacar que en la mayoría de los países del TOP 10 el nivel de desarrollo tecnológico o de los sistemas bancarios es alto, lo que captura la atención de los delincuentes cibernéticos.

En Rusia el 0,75\% de los usuarios se topó por lo menos una vez con troyanos bancarios; en EE.UU., el 0,89\%; en España, el $2,02 \%$, en Inglaterra, el 1,58\% y en Alemania, el 1,16\%.

\section{Amenazas financieras}

Las amenazas financieras no se limitan al malware bancario que ataca a los clientes de los sistemas de banca online.

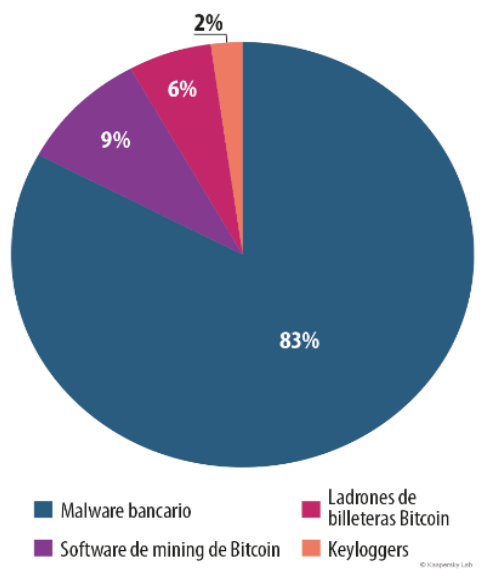

Número de ataques del software malicioso financiero

En comparación con el trimestre anterior, ha aumentado la cantidad de software bancario malicioso, del $71 \%$ al $83 \%$. La segunda amenaza financiera más popular en el segundo trimestre fueron los miners de Bitcoin, software malicioso que aprovecha la potencia del equipo de la víctima para generar bitcoins. El trimestre anterior esta categoría de malware estaba en el tercer puesto. Cabe destacar que algunos desarrolladores de software legítimo también instalan programas de minado de Bitcoin_en sus aplicaciones.

\section{TOP-10 de objetos detectados en Internet}

Durante el segundo trimestre de 2015 el antivirus web detectó 26084253 objetos maliciosos únicos (scripts, exploits, ficheros ejecutables, etc.).

TOP 10 de objetos detectados en Internet

\begin{tabular}{cc}
\hline Nombre $^{*}$ & $\begin{array}{c}\% \text { del total } \\
\text { de } \\
\text { ataques }^{* *}\end{array}$ \\
\hline 1 AdWare.JS.Agent.bg & $47,66 \%$
\end{tabular}




\begin{tabular}{llc}
2 & Malicious URL & $32,11 \%$ \\
\hline 3 & Trojan.Script.Generic & $4,34 \%$ \\
\hline 4 & AdWare.Script.Generic & $4,12 \%$ \\
\hline 5 & Trojan.Script.Iframer & $3,99 \%$ \\
\hline 6 & AdWare.JS.Agent.bt & $0,74 \%$ \\
\hline 7 Exploit.Script.Blocker & $0,56 \%$ \\
\hline 8 Trojan.Win32.Generic & $0,49 \%$ \\
\hline 9 & AdWare.AndroidOS.Xynyin.a & $0,49 \%$ \\
\hline 10 & $\begin{array}{l}\text { Trojan- } \\
\text { Downloader.Win32.Generic }\end{array}$ & $0,37 \%$ \\
\hline
\end{tabular}

*Veredictos de detección pertenecientes al módulo del antivirus web. Esta información la han hecho posible los usuarios de los productos de KL que expresaron su consentimiento para la transmisión de datos estadísticos. ** Porcentaje del total de ataques web registrados en los computadoras de usuarios únicos.

La agresiva propagación de programas publicitarios se ha reflejado una vez más en esta estadística: diez de las veinte posiciones las ocupan objetos que se clasifican como programas publicitarios. El primer puesto lo ocupa el script AdWare.JS.Agent.bg, que los programas publicitarios inyectan al azar en páginas web. Este último hasta ha logrado desplazar a Malicious URL, un veredicto para enlaces de la lista negra que ocupó el segundo puesto según los totales del trimestre.

El veredicto Trojan-Ransom.JS.Blocker.a es un script que mediante la renovación cíclica de la página trata de bloquear el navegador y muestra un mensaje de que es necesario pagar una "multa" a determinada billetera electrónica por haber visto materiales indebidos. Este script se suele encontrar con mayor frecuencia en los sitios de pornografía.

\section{Países-fuente de ataques web: Top 10}

Esta estadística muestra la distribución según país de las fuentes de ataques web bloqueados por el antivirus en las computadoras de los usuarios (páginas web con redirecciones a exploits, sitios con exploits y otros programas maliciosos, centros de administración de botnets, etc.). Hacemos notar que cada host único puede ser fuente de uno o más ataques web.

Para determinar el origen geográfico de los ataques web Kaspersky Lab usó el método de comparación del nombre de dominio con la dirección IP real donde se encuentra el dominio dado y la definición de la ubicación geográfica de la dirección IP (GEOIP).

El segundo trimestre de 2015 las soluciones de Kaspersky Lab han neutralizado 379972834 ataques lanzados desde recursos de Internet ubicados en diferentes países del mundo. El $89 \%$ de las notificaciones sobre ataques web bloqueados se obtuvo durante el bloqueo de los ataques lanzados desde recursos web ubicados en diez países.

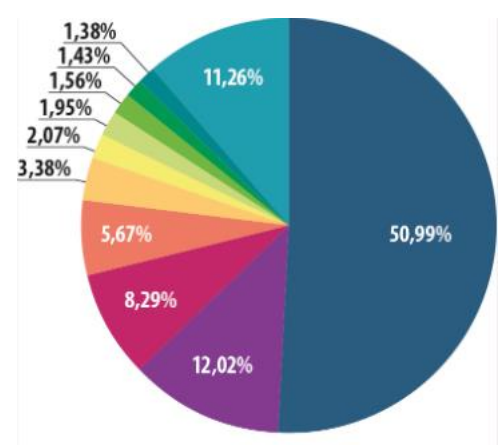

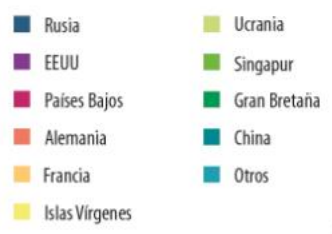

\section{Distribución por países de las fuentes de ataques web,} segundo trimestre de 2015

El líder de nuestra estadística no ha cambiado y sigue siendo Rusia $(51 \%)$, con una participación que aumentó en un $11,27 \%$. Suiza, que estaba presente en el TOP 10 del trimestre anterior, lo ha abandonado. En el octavo puesto, con un índice del 1,56\% está Singapur.

\section{Países en los cuales los usuarios han estado bajo mayor riesgo de infectarse mediante Internet}

Para evaluar el riesgo de infección a través de Internet al que están expuestos las computadoras de los usuarios en diferentes países del mundo, han calculado con qué frecuencia durante el año los usuarios de los productos de Kaspersky Lab en cada país se han topado con la reacción del antivirus web. Los datos obtenidos son el índice de la agresividad del entorno en el que funcionan las computadoras en diferentes países.

\begin{tabular}{lll}
\hline & País $^{*}$ & $\begin{array}{l}\% \text { de usuarios } \\
\text { únicos }\end{array}$ \\
\hline 1 & Rusia & $38,98 \%$ \\
\hline 2 & Kazajistán & $37,70 \%$ \\
\hline 3 & Ucrania & $35,75 \%$ \\
\hline 4 & Siria & $34,36 \%$ \\
\hline 5 & Bielorrusia & $33,02 \%$ \\
\hline 6 & Azerbaiyán & $32,16 \%$ \\
\hline 7 & Tailandia & $31,56 \%$ \\
\hline 8 & Georgia & $31,44 \%$ \\
\hline 9 & Moldavia & $31,09 \%$ \\
\hline 10 & Vietnam & $30,83 \%$ \\
\hline
\end{tabular}

La presente estadística contiene los veredictos de detección del módulo del antivirus web que enviaron los usuarios de los 
productos de Kaspersky Lab que dieron su consentimiento para el envío de datos estadísticos.

**Porcentaje de usuarios únicos que fueron víctimas de ataques web, de entre todos los usuarios únicos de los productos de Kaspersky Lab en el país.

En el segundo trimestre de 2015 Rusia ha vuelto a ocupar el primer puesto, subiendo desde el segundo que ocupaba el trimestre anterior.

Entre los países más seguros para navegar en Internet están Argentina (13,2\%), los Países Bajos (12,5\%), Corea (12,4\%), Suecia $(11,8 \%)$, Paraguay $(10,2 \%)$ y Dinamarca $(10,1 \%)$.

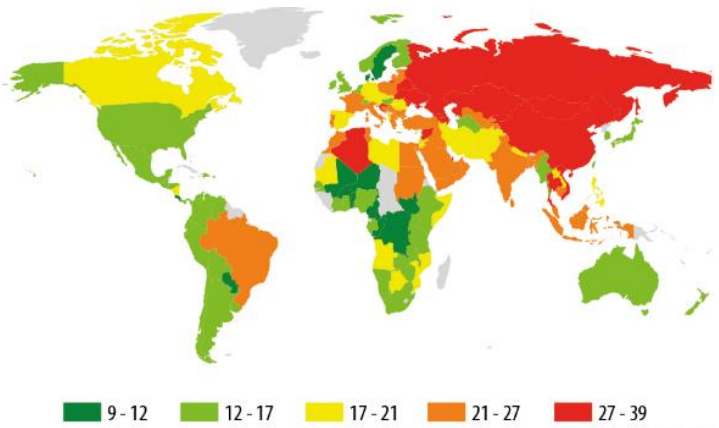

En promedio, durante el trimestre el $23,9 \%$ de los computadoras en el mundo ha sufrido por lo menos un ataque web.

\section{Amenazas locales}

Un indicador crucial es la estadística de infecciones locales de las computadoras de los usuarios. En estos datos se enumeran los objetos que han entrado en el equipo infectando archivos o memorias extraíble, o aquellos que inicialmente entraron en forma velada (por ejemplo los programas incluidos en los instaladores complejos, archivos cifrados, etc.).

Kaspersky Lab analiza los datos estadísticos obtenidos del funcionamiento del antivirus que escanea los ficheros en el disco duro en el momento en que se los crea o cuando se los lee, y los datos del escaneo de diferentes memorias extraíbles.

El segundo trimestre de 2015 el antivirus para ficheros ha detectado 110731713 diferentes programas nocivos y potencialmente indeseables.

\section{Objetos detectables encontrados en los computadoras de los usuarios: Top 10}

\begin{tabular}{lll}
\hline Nombre* & $\begin{array}{l}\% \text { de usuarios } \\
\text { únicos } \\
\text { atacados** }\end{array}$ \\
\hline 1 & DangerousObject.Multi.Generic & $22,64 \%$ \\
\hline 2 & Trojan.Win32.Generic & $15,05 \%$ \\
\hline 3 & Trojan.WinLNK.StartPage.gena & $8,28 \%$ \\
\hline
\end{tabular}

\begin{tabular}{lll}
4 & AdWare.Script.Generic & $7,41 \%$ \\
\hline 5 & Adware.NSIS.ConvertAd.heur & $5,57 \%$ \\
\hline 6 & WebToolbar.Win32.Agent.azm & $4,48 \%$ \\
\hline 7 & WebToolbar.JS.Condonit.a & $4,42 \%$ \\
\hline 8 & $\begin{array}{l}\text { Trojan- } \\
\text { Downloader.Win32.Generic }\end{array}$ & $3,65 \%$ \\
\hline 9 & Downloader.Win32.MediaGet.elo & $3,39 \%$ \\
\hline 10 & Trojan.Win32.AutoRun.gen & $3,29 \%$ \\
\hline
\end{tabular}

*Veredictos de detección de los módulos OAS y ODS del antivirus, que fueron proporcionados por los usuarios de los productos de Kaspersky Lab que dieron su consentimiento para la transmisión de datos estadísticos. ${ }^{* *}$ Porcentaje de usuarios únicos en cuyos computadoras el antivirus detectó este objeto, del total de usuarios únicos de los productos de Kaspersky Lab y en los que ocurrió la detección.

\section{Países en los que las computadoras de los usuarios han estado bajo mayor riesgo de infección local}

Para cada uno de los países hemos calculado qué porcentaje de usuarios de los productos de Kaspersky Lab se ha topado con las reacciones del antivirus de ficheros durante el periodo que abarca el informe. La presente estadística refleja el nivel de infección de las computadoras personales en diferentes países del mundo.

TOP 10 de países según su cantidad de computadoras infectados

\begin{tabular}{llr}
\hline & \multicolumn{1}{c}{ País* } & $\begin{array}{c}\% \text { de } \\
\text { usuarios } \\
\text { únicos** }\end{array}$ \\
\hline 1 & Bangladesh & $60,53 \%$ \\
\hline 2 & Vietnam & $59,77 \%$ \\
\hline 3 & Pakistán & $58,79 \%$ \\
\hline 4 & Mongolia & $58,59 \%$ \\
\hline 5 & Georgia & $57,86 \%$ \\
\hline 6 & Somalia & $57,22 \%$ \\
\hline 7 & Nepal & $55,90 \%$ \\
\hline 8 & Afganistán & $55,62 \%$ \\
\hline 9 & Argelia & $55,44 \%$ \\
\hline 10 & Armenia & $55,39 \%$ \\
\hline
\end{tabular}

La presente estadística contiene los veredictos de detección del antivirus que proporcionaron los usuarios de los productos de Kaspersky Lab que dieron su consentimiento para el envío de datos estadísticos. Han tomado en cuenta los programas maliciosos encontrados directamente en los computadoras de los usuarios o en las memorias extraíbles conectadas a éstos: memorias USB, tarjetas de memoria de cámaras, teléfonos y discos duros externos. ** Porcentaje de usuarios únicos en cuyos computadoras se detectaron amenazas locales, de entre la cantidad total de usuarios de productos de Kaspersky Lab en el país. 
Este trimestre Bangladesh ocupa el primer puesto con un $60,53 \%$, desplazando al segundo puesto a Vietnam, que fue el líder durante los dos últimos años. Pakistán (58,79\%) subió del puesto 13, que ocupaba el trimestre pasado, al tercero.

Los nuevos de la estadística son Georgia, que de entrada ocupó el quinto lugar (57,8\%); Rusia, que ocupa el undécimo puesto (55\%); Túnez el decimosexto $(53,7 \%)$ y Ucrania el decimonoveno (53\%).

Los países con el menor nivel de infección son Suecia $(19,7 \%)$, Dinamarca $(18,4 \%)$ y Japón $(15,5 \%)$.

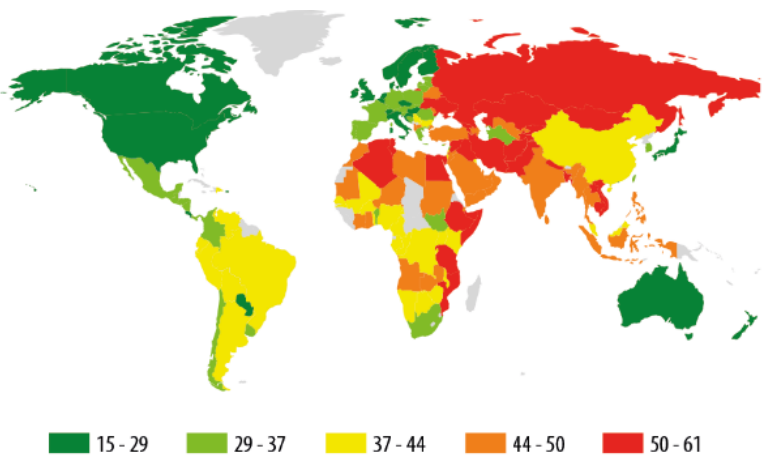

En promedio, en el mundo por lo menos una vez durante el trimestre se detectaron amenazas locales en el $40 \%$ de los equipos de los usuarios, un $0,2 \%$ más que en el primer trimestre.

\section{Análisis:}

Para el análisis se ha considerado la información de Kaspersky Lab del 2do. Trimestre 2015, en donde se extrae información de los cuadros con información y de allí se proponemos que existe una correlación entre sus variables de infección como de intentos por los virus informáticos y los países más vulnerables por lo que utilizamos el método ACP

El ACP es un método algebraico/estadístico que trata de sintetizar y dar una estructura a la información contenida en una matriz de datos.

En el ACP, el primer factor o componente sería aquel que explica una mayor parte de la varianza total, el segundo factor sería aquel que explica la mayor parte de la varianza restante, es decir, de la que no explicaba el primero y así sucesivamente. De este modo sería posible obtener tantos componentes como variables originales.

El siguiente paso consiste en la obtención de los valores y vectores propios de la matriz de covarianzas muestral o de la matriz de coeficientes de correlación que se obtienen a partir de la matriz de datos. La elección de una u otra matriz para realizar el ACP es una cuestión controvertida. En este caso vamos a utilizar la matriz de correlaciones.

Se ha identificado a los países más vulnerables con las variables de los virus informáticos atacados o con intentos de infección ya sea móviles o a Pc's.

\begin{tabular}{|l|r|r|r|r|} 
& & & & \\
& $\begin{array}{l}\text { usuarios } \\
\text { atacados por } \\
\text { los troyanos } \\
\text { bancarios } \\
\text { móviles** }\end{array}$ & $\begin{array}{l}\text { usuarios } \\
\text { atacados por } \\
\text { lo menos con } \\
\text { un intentos de } \\
\text { infección }\end{array}$ & $\begin{array}{l}\text { usuarios que } \\
\text { han estado bajo } \\
\text { mayor riesgo de } \\
\text { infectarse } \\
\text { mediante } \\
\text { Internet* }\end{array}$ & $\begin{array}{l}\text { usuarios en los que } \\
\text { los ordenadores de } \\
\text { los usuarios han } \\
\text { estado bajo mayor } \\
\text { riesgo de infección } \\
\text { local }\end{array}$ \\
\hline Argelia & 15525 & 1902.6669 & 1096221.626 & 613896.6169 \\
\hline Bielorrusia & 61.179 & 1641.6365 & 1254670.298 & 670259.0588 \\
\hline China & 50.9825 & 3332.2162 & 1052524.75 & 640693.6914 \\
\hline Corea del Sur & 483.3141 & 1521.3178 & 1171456.247 & 661843.4486 \\
\hline Rusia & 177.4191 & 1735.4443 & 1481134.107 & 608360.0312 \\
\hline Ucrania & 59.1397 & 1710.9727 & 1358402.882 & 586988.8106 \\
\hline Uzbekistán & 73.4148 & 1745.6408 & 1432497.584 & 600498.0796 \\
\hline
\end{tabular}

En la salida de resultados se ha utilizado el software libre $R$ Statistics y con él a través del interface gráfica de Rcommander se ha instalado un "plug in" de Minería de Datos que es el Rattle, herramientas que han ayudado para los cálculos, se observan varias gráficas descriptivas exploratorias donde se presentan varios datos.

El siguiente paso consiste en la obtención de los valores y vectores propios de la matriz de covarianzas muestral o de la matriz de coeficientes de correlación que se obtienen a partir de la matriz de datos.

En este caso vamos a utilizar la matriz de correlaciones.

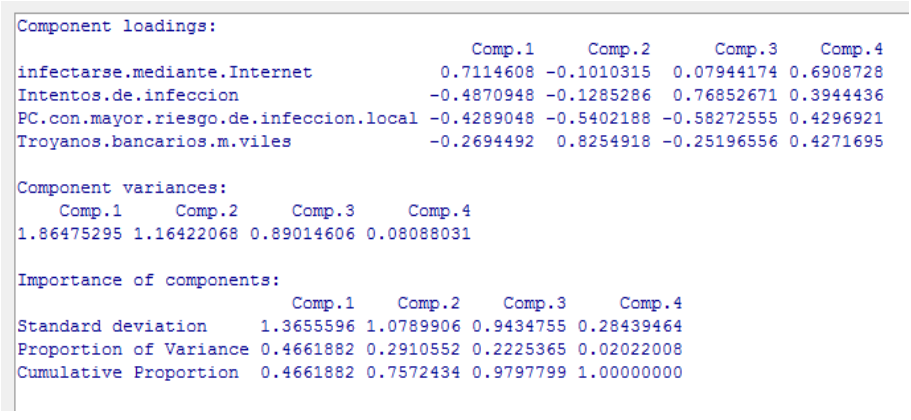

Los otros elementos importantes en un ACP son los vectores propios asociados a cada valor propio.
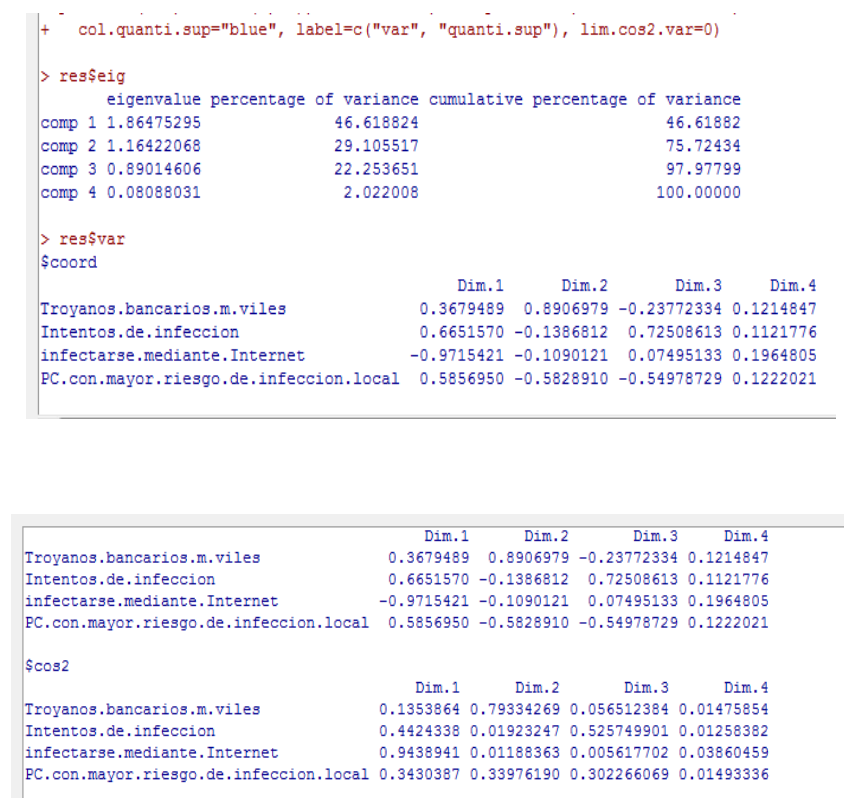
Cada columna representa una combinación lineal (loadings) de las variables originales que proporcionan las componentes principales o factores. Así el primer componente se obtiene con la siguiente combinación:

$\mathrm{F} 1=0.3679489$ troyanos +0.6651570 intentos de infección0.9715421 infectarse mediante internet +0.5856950 PC con mayor riesgo de infección

La determinación del número de factores a retener es, en parte, arbitraria y queda a juicio del investigador. Un criterio es retener los factores con valor propio superior a 1.

La carga del factor es la correlación existente entre una variable original y un factor, obtenido por combinación lineal de las variables originales.

Estas correlaciones se pueden calcular como producto de los coeficientes o loadings y las desviaciones de cada componente:

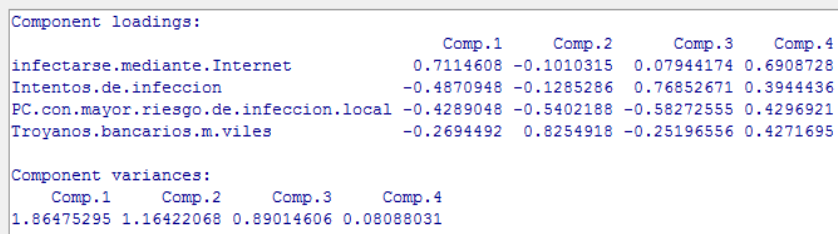

Variables factor map (PCA)

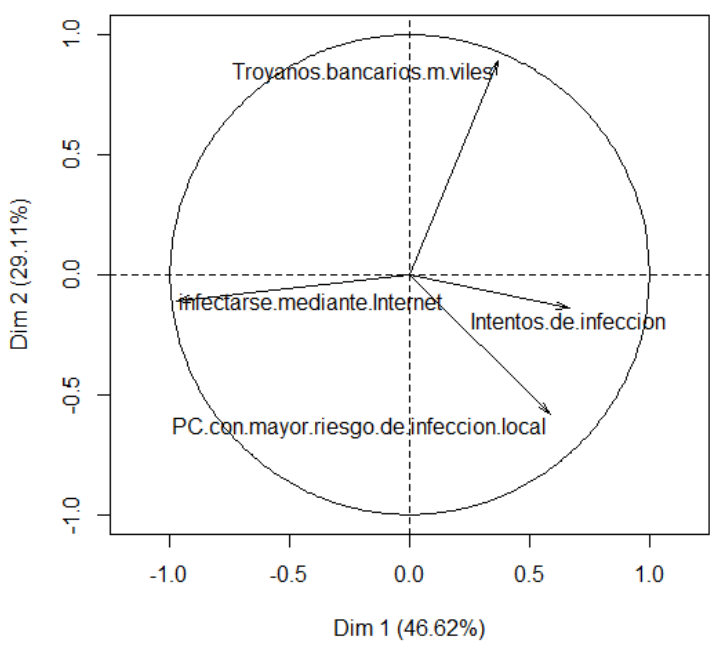

La comunalidad es un valor que se obtiene en el análisis factorial, para cada una de las variables originales, sumando los cuadrados de las correlaciones o cargas de los factores retenidos con la variable para la que se calcula y que expresa la proporción de varianza de la variable extraída o explicada con $\mathrm{m}$ factores, donde $\mathrm{m}$ es el número de factores retenidos. Si $\mathrm{m}$ es igual al número total de variables la comunalidad será igual a 1.

Los cosenos son las correlaciones al cuadrado y su acumulación proporciona las comunalidades.

Observamos también que existe 3 clúster

Se identifican los clústeres de los países. Como se puede observar, se marcaron los 3 clústeres o conglomerados. La siguiente tabla presenta la composición de los clústeres mencionados:

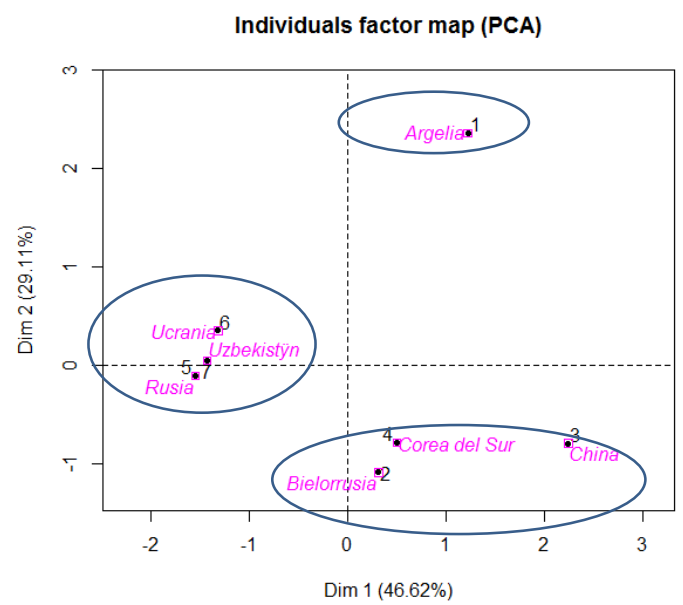

\begin{tabular}{ll}
\hline Clúster & \multicolumn{1}{c}{ Individuos } \\
\hline $\mathbf{1}$ & Ucrania, Uzbekistan, Rusia \\
$\mathbf{2}$ & Bielorrusia, Corea del Sur, China \\
$\mathbf{3}$ & Argelia \\
\hline
\end{tabular}

Ahora analizamos las variables del factor map (PCA), para ello utilizamos solo los 2 componentes por contar con buena variación

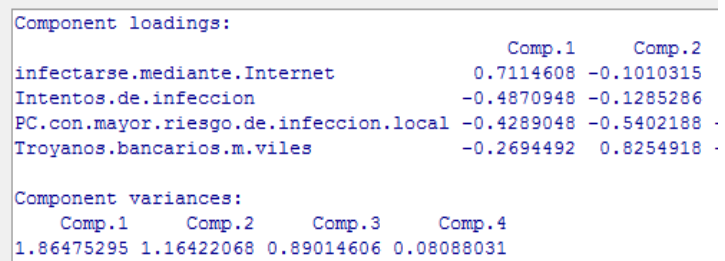


Y observando el círculo de correlaciones podemos concluir

- Que las "PC con mayor riesgo de infección local" con "intentos de infección" están cercanas entre sí, entonces son positivamente correlacionadas (si estuvieran estas aristas muy cerca significaría que serían fuertemente correlacionadas)

- También observamos que las "PC con mayor riesgo de infección local" con "intentos de infección" y "Troyanos bancarios móviles" es cercano a los $90^{\circ}$ entonces no existe ninguna correlación entre ambas variables

- Mientras que las "PC con mayor riesgo de infección local" con "infectarse con internet" están casi opuestas al vértice entonces podemos afirmar que existe una correlación negativa, sin embargo entre las variables de "infectarse con internet" e "intentos de infección" existe una fuerte y negativa correlación.

Ahora aplicamos la Inercia Explicada: Proporción de la cantidad de inercia de cada eje con respecto a la inercia total Indica la importancia de las dimensiones representadas en cada uno de los ejes del mapa
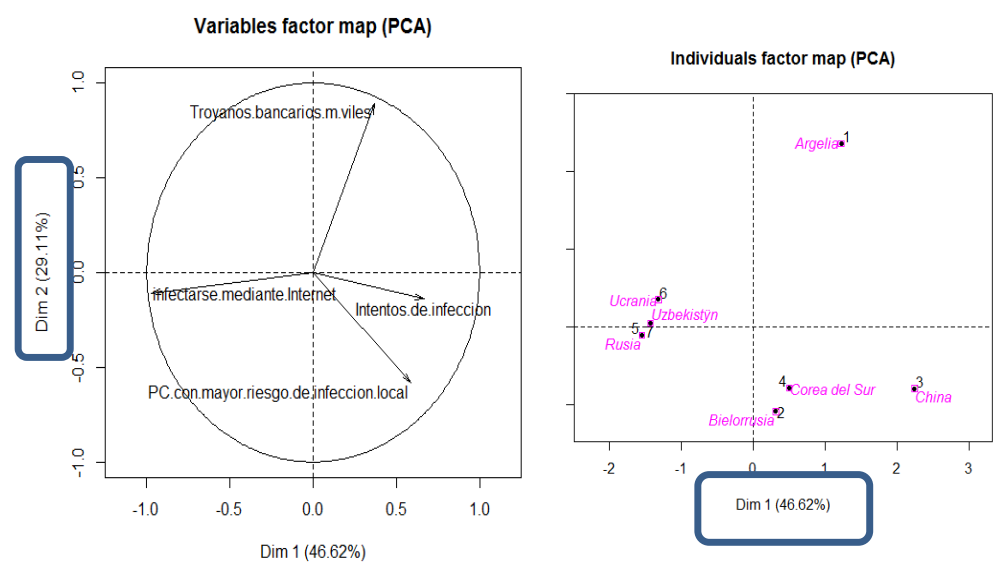

En este caso la Inercia explicada es $46.62 \%+29.11 \%=$ $75.73 \%$, significa que la dispersión de información del estudio se encuentra en $75.73 \%$, es decir lo que se estudia está solo a un $75.73 \%$ de toda la información, lo que se está dejando de estudiar es $24.27 \%$.

También se observa que la mejor dimensión es $75.73 \%$ que es una asociación entre las variables es altamente significativa.

Mientras que para la calidad de representación de cada variable sobre el círculo de correlaciones, será medida con el coseno cuadrado del ángulo de la variable y su proyección, ahora bien entre las variables el coseno es igual a su correlación, por lo que las correlaciones cercanas a 1 son las que impliquen la calidad de la representación de las variables, es decir estarán bien representadas aquellas variables que queden ubicadas cerca de la frontera o borde del círculo de correlaciones

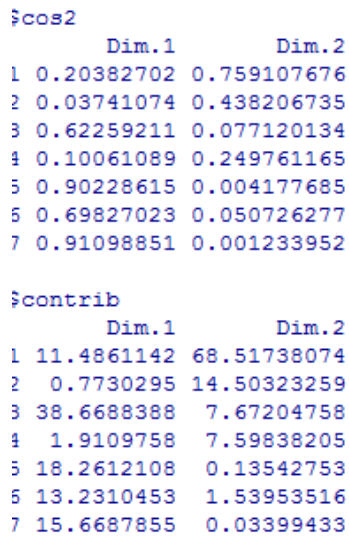

Entonces vemos de acuerdo al ángulo del coseno quevariables están cercanas a 1 como que también cuales están alejadas, que serán las que tiene menos representación en éste plano, para ello realizamos el cálculo:

\begin{tabular}{|r|r|r|r|}
\hline \multicolumn{2}{|c|}{ Dim.1 } & \multicolumn{1}{|c|}{ Dim.2 } & \multicolumn{1}{l|}{ Suma*100 } \\
\hline 1 & 0.2036 & 0.7591 & 96.27 \\
\hline 2 & 0.3741 & 0.4362 & 81.03 \\
\hline 3 & 0.6226 & 0.0712 & 69.38 \\
\hline 4 & 0.1006 & 0.2498 & 35.04 \\
\hline 5 & 0.9023 & 0.0042 & 90.65 \\
\hline 6 & 0.6963 & 0.0507 & 74.7 \\
\hline 7 & 0.9109 & 0.0012 & 91.21 \\
\hline
\end{tabular}

La variable 4 que es del país Corea del Sur es la que tiene menos representación en este plano, mientras que los demás países si están bien representado en el plano.
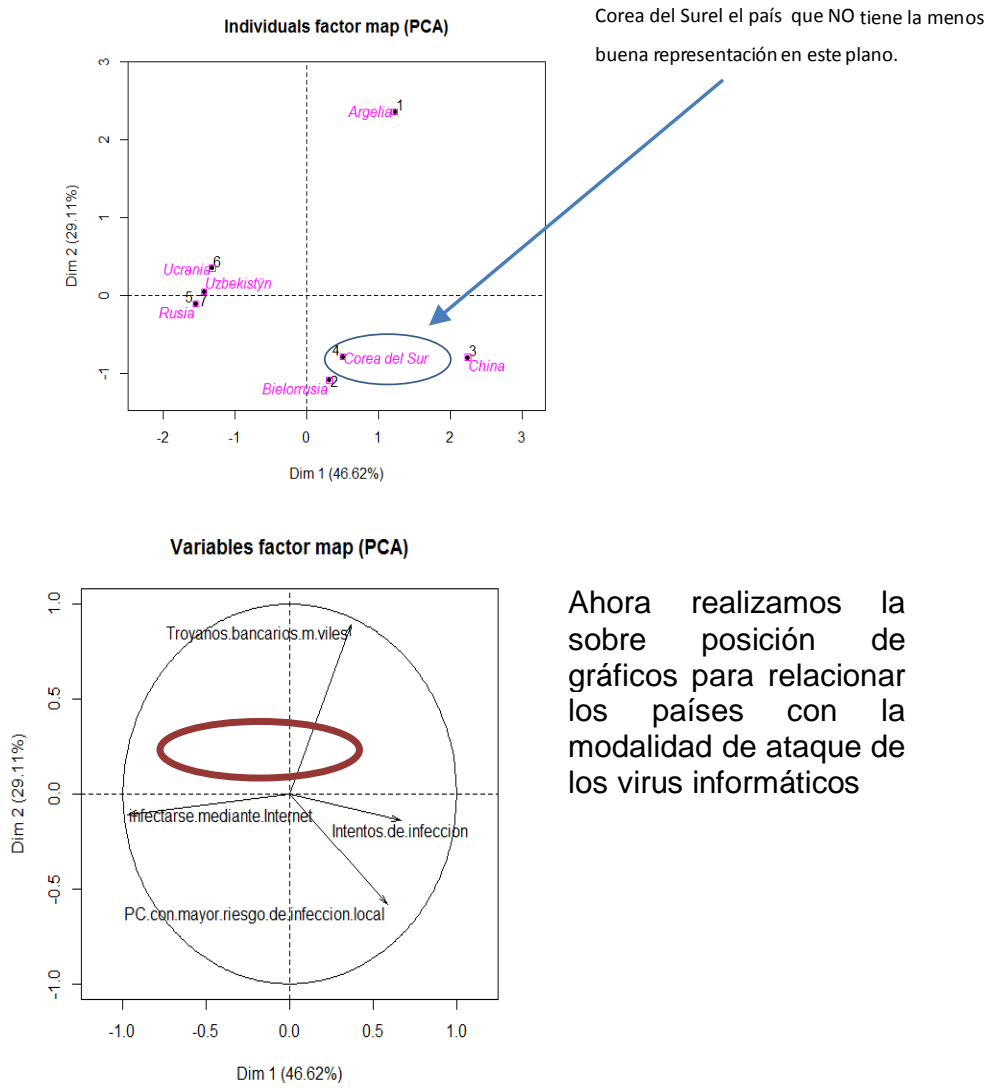

Ahora realizamos la sobre posición de gráficos para relacionar los países con la modalidad de ataque de los virus informáticos 
central t-distributions applied in microarray data analysis". Computational Statistics and Data Analysis (2012).

[3] Santesmases, Miguel. Diseño y análisis de encuestas en investigación social y de mercados, Ed. Pirámide, Madrid, 2009.

[4] Peña, D. (2002). Análisis de Datos Multivariantes, McGraw Hill, Madrid. 